\title{
Política educacional e o transporte escolar na rede pública de educação: um estudo de caso na gerência regional do Agreste Meridional de Pernambuco
}

\author{
Educational policy and school transportation in the public education system: a case study in the
} Southern Agreste regional management of Pernambuco

Política educativa y transporte escolar en la red pública de enseñanza: un estudio de caso en la gestión regional Agreste del sur de Pernambuco

Stella Maria do Nascimento ORCID: https://orcid.org/0000-0003-0967-7344 Universidade de Pernambuco, Brasil E-mail: stella.nascimento@upe.br

Karine Rosália Felix Praça Gomes ORCID: https://orcid.org/0000-0003-3491-1606 Universidade de Pernambuco, Brasil E-mail: karine.rosalia@upe.br José Luiz Alves

ORCID: https://orcid.org/0000-0003-2049-2084 Universidade de Pernambuco, Brasil E-mail: jlzalves@yahoo.com.br

José de Lima Albuquerque ORCID: https://orcid.org/0000-0003-0625-5656 Universidade Federal Rural de Pernambuco, Brasil E-mail: limalb53@gmail.com

Ana Claudia Dantas Cavalcanti ORCID: https://orcid.org/0000-00-2-9498-704X Universidade Federal da Grande Dourados, Brasil E-mail: anacavalcanti@ufgd.edu.br

Viviane Paula Correia Duarte

ORCID: https://orcid.org/0000-0002-1319-601X Gerência Regional de Educação Agreste Meridional Garanhuns, Brasil

E-mail: viviane.silva@adm.educacao.pe.gov.br

Felipe de Luna Berto

ORCID: https://orcid.org/0000-0001-6109-3026 Gerência Regional de Educação Agreste Meridional Garanhuns, Brasil E-mail: felipebe@educacao.pe.gov.br

Adelma Elias da Silva

ORCID: https://orcid.org/0000-0002-3476-8961 Gerência Regional de Educação Agreste Meridional Garanhuns, Brasil E-mail: gabinetegream.assessoria@hotmail.com

Sinésio Monteiro de Melo Filho

ORCID: https://orcid.org/0000-0001-9279-735X

Gerência de Articulação Municipal, Brasil

E-mail: gameducacaope@gmail.com

\begin{abstract}
Resumo
O transporte escolar não é apenas um direito, mas é uma questão de cidadania. O presente estudo teve como objetivo identificar principais irregularidades que ocasionam a paralisação dos serviços, a partir do próprio usuário desse serviço público, para saber como estão sendo ofertados os meios para garantir o seu direito de acesso e permanência na escola por meio do exame da aplicação dos instrumentos de monitoramento dos serviços de transporte escolar na Região do Agreste Meridional do Estado de Pernambuco. Para isso, foi realizada uma pesquisa de campo de caráter descritivo exploratório, que se justifica e é fundamentada em uma verificação de literatura composta por pesquisa bibliográfica, documental e estudo de caso. O instrumento aplicado foi a realização de um questionário a uma dada população. Ele mediu de forma quantitativa as atividades relacionadas a esta variável. Com esse monitoramento foram detectados problemas sejam repetidos ou ocasionais, os quais feriram o que determina a legislação da política pública de transporte escolar. Com os resultados configurou-se a seguinte irregularidade: paralisação dos serviços. Com isso, fez-se necessário urgentemente implementar novos elementos na gestão de monitoramento dos serviços de transporte escolar, da Gerência de Articulação Municipal (GAM/SEE) juntamente com as Gerências Regionais de Educação.
\end{abstract}


Palavras-chave: Educação; Transporte escolar; Programa Estadual de Transporte Escolar de Pernambuco.

\begin{abstract}
School transportation is not only a right, but a matter of citizenship. The present study aimed to identify the main irregularities that cause the paralysis of services, from the very user of this public service, to know how the means are being offered to ensure their right of access and permanence in school through the examination of the application of the monitoring instruments of school transport services in the Southern Agreste Region of the State of Pernambuco. For this, it was carried out a field research of exploratory descriptive character, which is justified and based on a literature verification composed by bibliographic and documental research and case study. The instrument applied was a questionnaire to a given population. It quantitatively measures the activities related to this variable. With this monitoring, problems were detected, whether repeated or occasional, which hurt what determines the legislation of the public policy of school transport. With the results, the following irregularity is configured: paralysis of services. Thus, it is urgently necessary to implement new elements in the management monitoring of school transportation services, from the Municipal Articulation Management (GAM/SEE) along with the Regional Education Managers.
\end{abstract}

Keywords: Education; School transportation; State Program of School Transportation of Pernambuco.

\title{
Resumen
}

El transporte escolar no es sólo un derecho, sino también una cuestión de ciudadanía. El presente estudio tuvo como objetivo identificar las principales irregularidades que causan la paralización de los servicios, a partir del usuario de este servicio público, para saber cómo se están ofreciendo los medios para garantizar su derecho de acceso y permanencia en la escuela a través del examen de la aplicación de los instrumentos de seguimiento de los servicios de transporte escolar en la Región Agreste Sur del Estado de Pernambuco. Para ello, se llevó a cabo una investigación de campo de carácter descriptivo exploratorio, que se justifica y se basa en una verificación de la literatura compuesta por la investigación bibliográfica y documental y el estudio de casos. El instrumento aplicado fue la realización de un cuestionario a una población determinada. Medía de forma cuantitativa las actividades relacionadas con esta variable. Con este seguimiento, se detectaron problemas, repetidos u ocasionales, que perjudican la legislación de la política pública de transporte escolar. Con los resultados se configuró la siguiente irregularidad: paralización de servicios. Por lo tanto, fue necesario implementar urgentemente nuevos elementos en la gestión de monitoreo de los servicios de transporte escolar, desde la Gerencia de Articulación Municipal (GAM/SEE) junto con las Gerencias Regionales de Educación.

Palabras clave: Educación; Transporte escolar; Programa Estatal de Transporte Escolar de Pernambuco.

\section{Introdução}

O presente estudo tomou por base a trajetória histórica e evolutiva das políticas públicas para embasamento da política pública de transporte escolar. Na trajetória das políticas públicas constatou-se que os processos de formulação e implementação dessas políticas, destacavam-se pela natureza de centralidade de sua dimensão intersetorial e integrativa, ou seja, complementavam-se e interagiam para atender os anseios e necessidades da sociedade, numa efetiva articulação e colaboração entre os entes federados.

Nesse sentido, as políticas públicas têm por base: as políticas econômicas, alterando-se de acordo com a variação da economia; decisão e vontade política dos governantes frente ao papel do Estado junto à sociedade; o nível de atuação dos diferentes grupos sociais.

Na acepção de Secchi (2020) política pública é um conceito abstrato que se materializa com instrumentos concretos tais como: leis, programas, campanhas, obras, prestação de serviço, subsídios, impostos e taxas, decisões judiciais, entre outros. Diante disso, várias tentativas explicativas vêm sendo empregadas com o intuito de deixar mais claro o entendimento. A exemplo de pesquisas como de Benicio et al. (2020), que conceituam o termo de uma forma geral a partir do aparelho estatal ou, conforme níveis de classificação do processo de sua formulação. Todavia, é necessário ressaltar que a concepção de política pública adotada está estreitamente relacionada ao conceito e entendimento de Estado que se tem.

Assim, entendeu-se por política pública as disposições, medidas e procedimentos que traduziam a orientação política do Estado e regulavam as atividades governamentais relacionadas às tarefas de interesse público. Refletindo a ação intencional do Estado junto à sociedade em longo prazo. Segundo destacam Viegas et al. (2020) a política pública se efetiva a partir de um processo de tomada de decisões que envolve órgãos públicos e diferentes organismos e agentes da sociedade relacionados à 
política implementada. Também pode ser entendida como um sistema de ações sociais que compreende um esforço da sociedade principalmente das instituições para garantir de forma permanente os direitos à cidadania, especialmente aos cidadãos que estão na linha de pobreza, esquecidos no mundo dos políticos. Assim sendo, a política assume feições variadas em diferentes contextos e concepções de Estado e sociedade.

Daí a necessidade de se estabelecer políticas públicas adequadas a todos os contextos, o ato da formulação de políticas requer definição de metas, objetivos e recursos com clareza e objetividade, quanto ao ato da implementação às políticas transformam- se em programas que devem ser monitorados através de indicadores: eficácia sobre os meios e recursos empregados, ou seja, o tempo utilizado para o alcance do objetivo e metas do programa; eficiência para o cumprimento das metas na relação entre custo e benefícios, para social do programa efetividade relacionada aos resultados e objetivos, isto é, o impacto ou grau de alcance dos objetivos.

Tratar do tema política pública para a educação perpassa a compreensão de que uma das formas de classificar uma política educacional consiste em enquadrá-la em uma política de Estado ou política de governo (Neves \& Mesquita, 2020). Enquanto uma política de governo refere- se ao desenvolvimento de um plano, programa ou ação para vigorar durante um mandato de determinado governo, a política de Estado alude a um plano, programa ou ação com objetivos de longo prazo, elaborados para perdurarem além da execução de um mandato.

A Política Pública de Transporte Escolar tem como propósito assegurar o direito constitucional à educação a todos os estudantes matriculados na educação básica e que apresentam alguma dificuldade de deslocamento à escola, ou seja: moram em locais de difícil acesso; existência de grandes distâncias da residência até a escola; ou qualquer motivo que os impossibilitem de se locomover até a escola. No entendimento de Tavares (2019), a afirmação do transporte escolar como direito não deveria interferir na garantia de outro direito que é a educação do campo. Nesse sentido, o transporte escolar é parte integrante do direito à educação e não um eventual acessório.

De acordo com a Cartilha de Transporte Escolar. (MEC, 2005, p.7) transporte escolar é: um direito dos alunos que estudam longe de suas casas. Os alunos que moram no campo (áreas rurais) têm o mesmo direito ao transporte que os alunos que moram nas cidades (áreas urbanas); eficiente e seguro, caso todas as normas forem obedecidas; Prioridade para atender crianças que estudam da $1^{\circ}$ ao $9^{\circ}$ ano do ensino fundamental; Responsabilidade dos Estados e Municípios; realizado por veículos próprios, ou alugados pelos governos estaduais e prefeituras e por meio de passes escolares fornecidos aos alunos.

Ressalta-se que nessa conceituação da cartilha do MEC um item pouco explícito nos conceitos anteriores: a qualidade do transporte escolar, que se torna transparente no momento que trazemos para o aspecto conceitual do transporte escolar a eficiência e a segurança do mesmo.

Para dar cumprimento ao objetivo, que foi o de identificar as principais irregularidades que ocasionam a paralisação dos serviços, a partir do próprio usuário desse serviço público, para saber como estão sendo ofertados os meios para garantir o seu direito de acesso e permanência na escola por meio do exame da aplicação dos instrumentos de monitoramento dos serviços de transporte escolar na Região do Agreste Meridional do Estado de Pernambuco, o estudo estruturou-se da seguinte forma: na primeira parte do trabalho aparece a introdução. Posteriormente, a metodologia utilizada no trabalho. Na terceira parte apresentou-se o referencial teórico que fundamentou a investigação, seguida da análise dos dados. A última parte, a conclusão e recomendações para futuros trabalhos.

\section{Metodologia}

A investigação de natureza qualitativa foi elaborada por intermédio do embasamento teórico a respeito da política educacional e do transporte escolar na rede pública de educação. O enfoque qualitativo apresentado nesse estudo, de acordo com Fernandes et al. (2018) visou entender, descrever e explicar os fenômenos sociais de modos diferentes, através da análise 
de experiências individuais e grupais, exame de interações e comunicações que estivessem se desenvolvendo, assim como da investigação de documentos ou traços semelhantes de experiências e integrações. Assim, a pesquisa qualitativa caracterizou-se por ser interpretativa, baseada em experiências, situacional e humanística, sendo consistente com suas prioridades de singularidade e contexto.

A pesquisa caracterizou-se quanto aos fins como descritiva exploratória que se justificou pelo estudo ter se desenvolvido e fundamentado em uma verificação de literatura composta por pesquisa bibliográfica, documental, pela consulta a livros, e artigos relacionados ao tema: políticas públicas de transporte escolar. Quanto aos meios, caracterizou-se como um estudo de caso essa técnica segundo Alvares e Freitas (2018) caracteriza-se pelo nível de profundidade e detalhamento do fenômeno em questão, sendo ele recomendado para compreender dados fenômenos em espaços delimitados. Para isso, a unidade caso desse estudo foi a Gerência Regional do Agreste Meridional de Pernambuco.

Os instrumentos de coletas de dados deram-se por meio das bases de dados do Scielo e Google Acadêmico, as quais ampararam a fundamentação teórica, além do questionário aplicado em campo a uma dada população. De acordo com Pereira (2018) ele servirá para medir de forma quantitativa as atividades relacionadas a esta variável.

A investigação deteve-se a identificar a qualidade dos serviços contratados e prestados aos estudantes durante o ano de 2019, na Região do Agreste Meridional. Utilizando como referência o monitoramento: online semanal que teve como instrumento a Planilha de Ocorrência Semanal do Transporte Escolar, (POSTE) registro semanal da execução dos serviços de transporte escolar ofertados aos estudantes da educação básica em Pernambuco, e tem a finalidade de atualizar o banco de dados da Gerência de Articulação Municipal (GAM) com as principais ocorrências, para que, em tempo hábil, sejam tomadas as providências cabíveis, como também a pesquisa de satisfação dos estudantes com relação aos serviços prestados produzida, orientada e aplicada pela Gerência Regional de Educação do Agreste Meridional/Garanhuns através da Coordenação de Planejamento e Articulação (CGPA) e do Núcleo de Articulação Municipal (NAM).

Ressalta-se, porém, que esta investigação se resumiu em um estudo exploratório preliminar que pretende servir de alicerce para estudos futuros e mais aprofundados acerca do assunto em questão.

\section{Referencial Teórico}

\subsection{Educação uma questão de garantia fundamental}

O acesso à escola é o meio de se obter um grau maior de escolaridade ponto essencial para se competir no mercado de trabalho e contribuir com o desenvolvimento da sociedade que exige cada vez mais qualificação.

A Educação como direito fundamental está prevista no artigo $6^{\circ}$ da Constituição Federal integrando os direitos sociais, que está respaldado no Artigo 205 da Constituição Federal (1988). Embora a educação seja uma garantia constitucional, na prática esse direito não tem se efetivado. O Instituto Brasileiro de Geografia e Estatística (IBGE) informou no censo de 2018 que 50,2\% de brasileiros não possuem instrução ou tem fundamental incompleto (IBGE, 2019). Nesse aspecto, de um lado a Educação é direito das crianças e adolescentes, do outro é dever do Estado, que assegura além da oferta de ensino de qualidade, o efetivo acesso e permanência do estudante na escola. Assim, concebe-se que o dever do Estado vai além da matrícula do estudante na escola pública o que implica na oferta de meios.

Segundo Silva (2009, p.274) "proporcionar meios" implica no dever de criar "condições materiais para manter a permanência do estudante na escola." Corroborando com esse entendimento, Cruz et al (2008, p.2) estabelece uma conexão entre o transporte escolar o acesso e a permanência do estudante na escola ao dizer que o transporte escolar se refere ao serviço de transportar crianças e jovens de casa para escola e da escola para casa.

Estudos como os de Stein e Grigg (2019) reforçam que o transporte escolar pode afetar a assiduidade dos alunos na escola, no sentido de que alunos que utilizam o transporte escolar tendem a apresentar maior frequência, ao longo do ano 
letivo. A garantia de um meio que promova maior constância dos estudantes no ambiente escolar tem benefícios em aspectos de aprendizagem, já que maior frequência escolar está associada à melhores desempenhos acadêmicos.

É válido citar o estudo de Gottfried (2017) ao analisar o papel dos ônibus escolares como um instrumento redutor da ausência escolar dos estudantes, que iam para a escola utilizando o transporte escolar, esses alunos apresentaram menos dias de ausência durante o ano letivo em comparação com os alunos que utilizavam qualquer outra opção de transporte.

Logo, o transporte escolar não é apenas um direito, mas é uma questão de cidadania. Ao falar em cidadania estamos nos referindo às políticas públicas, através delas que se assegura a participação dos cidadãos nas ações governamentais, a cidadania é o meio através do qual o coletivo exerce seus direitos enquanto receptores e ao mesmo tempo tem o dever de contribuir no processo de elaboração implementação e monitoramento.

Portanto, a carência e a deficiência da oferta de transporte escolar público interferem no direito à igualdade de condições para o acesso e permanência na escola. No que se relaciona ao risco, a segurança e a vida das crianças e adolescentes no percurso casa-escola- casa, a precariedade do transporte escolar público ofertado deverá ser expulsa com urgência, para que se possa garantir efetivamente, o direito de acesso à escola e o cumprimento das demais normas vigentes.

\subsection{Transporte Escolar de Qualidade um Direito de Todos}

O transporte escolar dever do Estado e direito do estudante está assegurado na Constituição Federal/ 1988, no seu artigo 208 "O dever do estado com a educação será efetivado mediante a garantia de: VII- atendimento ao educando, em todas as etapas da educação básica, por meio de programas suplementares de material didático escolar, transporte alimentação e assistência à saúde.”

A política pública de transporte escolar no Brasil, enquanto instrumento da garantia de direito e cidadania é constituída a nível federal pelo Programa Nacional de Apoio ao Transporte Escolar - PNATE, instituído pela Lei nª 10.880, de 09 de junho de 2004, objetivo "garantir o acesso e a permanência nas unidades escolares, dos estudantes do ensino fundamental público residentes em área rural que utilizam transporte escolar, por meio de assistência financeira em caráter suplementar, aos estados Distrito Federal e municípios" (MEC, 2010). Com a Lei $n^{\circ} 11.947$, de 16 de junho de 2009, o programa passou a atender toda a educação básica, ampliando os serviços para os estudantes da educação infantil e do ensino médio residentes em áreas rurais, o que representa um número significativo de estudantes transportados e de altos investimentos que se traduzem nas despesas com manutenção de veículos escolares rodoviários manutenção de veículos escolares aquaviários, aquisição de passe estudantil quando existir oferta regular de transporte coletivo e pagamento de serviços oriundos de terceiros. É daí, que surge a preocupação com as questões de qualidade e segurança com relação aos serviços prestados em todo país.

A Lei de Diretrizes e Bases da Educação Nacional (LDB) nº 9.394, de 12/1996, prevê no seu artigo $4^{\circ}$ inciso VII, que o dever do estado com a educação escolar pública será efetivado mediante a garantia, no ensino fundamental público, do direito ao transporte escolar ao educando. Nesse sentido, Tavares (2019) afirma que apesar do caráter neoconservador e neoliberal que deu origem à LDB, essas garantias legais são indicativos importantes para a afirmação de uma política de transporte escolar. Corroborando com esse entendimento, reforçam Schuch et al. (2019) quando se trata de transporte escolar, a situação é agravada na zona rural, local em que a falta de investimentos ou melhorias em serviços básicos faz com que o morador do campo percorra grandes distâncias para ter acesso à escola mais próxima.

Todo o embasamento constitucional define as competências dos entes federativos no quesito transporte escolar: União - de acordo com os artigos $8^{\circ}, 9^{\circ}, \S 1^{\circ}$, cabe a União à coordenação da política nacional articulando os diferentes níveis e sistemas exercendo função normativa, redistributiva e supletiva em relação às demais estâncias educacionais; Estados - de acordo com artigo 10 inciso VII, cabe aos estados assumirem o transporte escolar dos estudantes da rede estadual; municípios: 
de acordo com o artigo 11 inciso VI, cabe aos municípios assumirem o transporte escolar dos estudantes da rede municipal. Além do que, as ações de apoio ao transporte escolar foram incluídas nos principais instrumentos de planejamento orçamentário brasileiro, que passou a ser regulado por três leis: Lei do Plano Plurianual (PPA), Lei de Diretrizes Orçamentárias (LDO), Lei Orçamentária Anual (LOA).

Nesse contexto, a implantação da política pública brasileira de transporte escolar necessita de cumprir os preceitos legais que disciplinam e regem a forma de utilização dos recursos financeiros que o Estado tem disponível. Seguindo essas premissas, o governo federal apoia o transporte escolar dos estudantes, com investimentos vinculados a manutenção e desenvolvimento do ensino, numa parceria com órgãos estaduais e municipais do segmento educação.

Enfatiza-se que é fundamental alocação de recursos financeiros, mas a política pública de transporte escolar vai mais além, ou seja, garantir aos estudantes desfrutar dos pré-requisitos básicos de qualidade do transporte escolar ofertado como: segurança regularidade, pontualidade, conforto, limpeza, cordialidade dentre outros. (Resolução TC/PE 06/2013) o que tornaria um transporte escolar público sustentável, dessa forma já atenderia a outro viés de prestação de serviços a sociedade com qualidade contribuindo para a sustentabilidade. Como complementaridade faz-se necessário a organização das rotas; o repensar na forma de atendimento aos estudantes; na educação no trânsito; na qualificação dos condutores dos veículos.

\subsection{Programa Estadual de Transporte Escolar (PETE) de Pernambuco no âmbito da Gerência Regional de Educação do Agreste Meridional/Garanhuns}

O Programa Estadual de Transporte Escolar (PETE) de Pernambuco instituído pela lei nº $13.463 / 2008$, alterada pela lei $\mathrm{n}^{\circ}$ 16.822/2020.A Constituição Estadual assegura no seu Artigo $177 \S 1^{\circ}$ a oferta pública dos serviços de transporte escolar aos estudantes da educação básica.

O Programa Estadual de Transporte Escolar consiste no repasse de recursos do Estado aos municípios que prestam serviços de transporte escolar aos estudantes da rede pública estadual de ensino residentes em área rural, com distância superior a 2,5 Km (dois virgula cinco quilômetros) da unidade de ensino com o objetivo de melhorar as condições de acesso á educação e garantir a permanência do estudante na escola, através de cooperação técnica e financeira com os Municípios ou por meio das Gerências Regionais de Educação. (NR)

$\S 1^{\circ}$ Para os fins desta Lei, poderão ser atendidos estudantes que não residam em área rural, quando matriculados em escolas situadas em localidades de difícil acesso e para as quais não há oferta de transportes alternativos. (AC)

$\S 2^{\circ}$ A oferta de transporte escolar para os estudantes regularmente matriculados na Rede Estadual de Educação, quando não atendidos pelos Municípios parceiros, ficará sob a responsabilidade da Secretaria de Educação e Esportes por meio das Gerências Regionais de Educação. (AC)

A transferência desses recursos financeiros no âmbito do (PETE) se dará a partir da formalização do Termo de Adesão entre o Estado de Pernambuco, através da Secretaria de Educação e as Prefeituras Municipais.

\section{Resultados e Discussão}

Frente ao desafio de monitorar sistematicamente a oferta dos serviços de transporte escolar vinculado ao Programa de Transporte Escolar (PETE), foram desenvolvidos, no âmbito da Gerência Regional de Educação do Agreste Meridional/Garanhuns, alguns instrumentos que aferiram a qualidade dos serviços na perspectiva de tomar providências, realizar ajustes em tempo hábil evitando o prejuízo no ensino aprendizagem dos estudantes.

Destacou-se a pesquisa de satisfação dos estudantes, que envolveu as escolas estaduais dos 22 municípios da jurisdição dessa Regional de Educação conforme ilustra o mapa da região representado na Figura 1 a seguir. 
Figura 1: Mapa da Região do Agreste Meridional/Garanhuns.

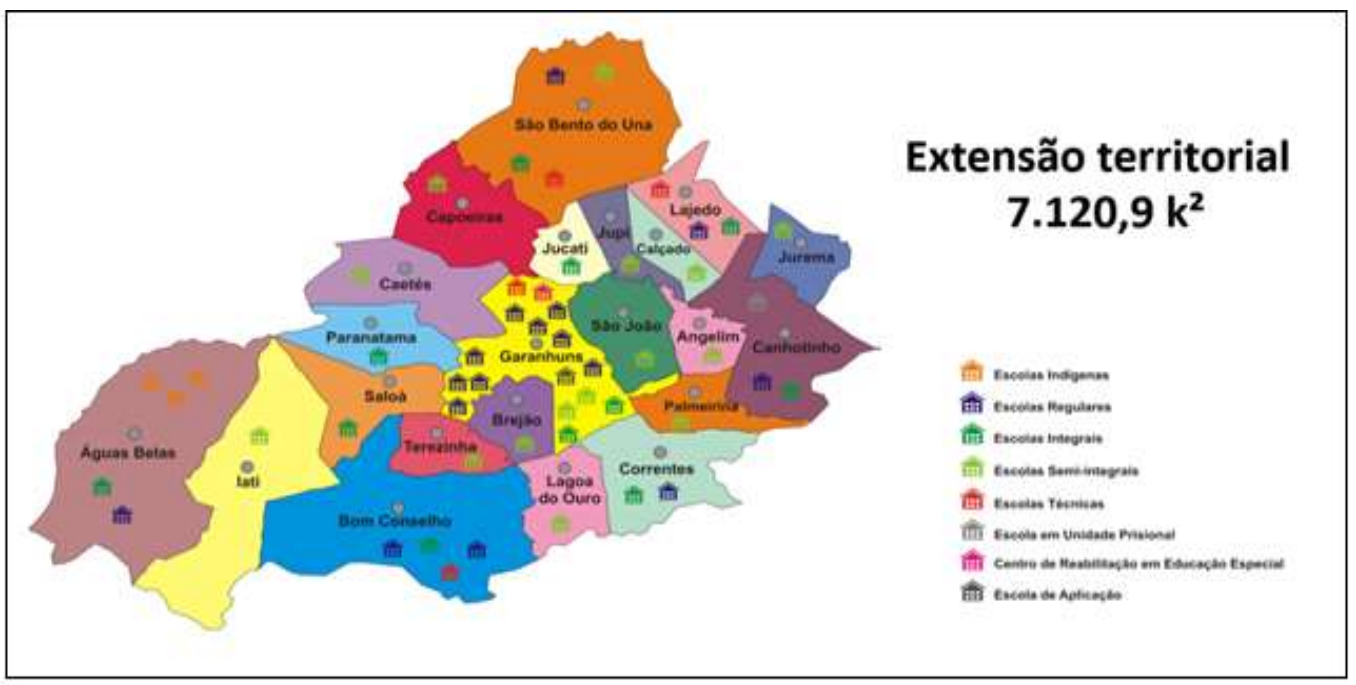

Fonte: Gerência de Articulação Municipal /SECO.

A ação teve o objetivo de proporcionar um espaço de escuta aos principais interessados na oferta de transporte escolar de qualidade. A pesquisa foi realizada no mês de setembro/2019, aplicação online do instrumento, sendo considerado um percentual de participação de $60 \%$ para uma atuação mais assertiva por parte da regional junto aos municípios. Participaram da pesquisa 5.806 estudantes das escolas estaduais dos 22 municípios jurisdicionados a esta regional, totalizando $61,26 \%$ do total de usuários do transporte escolar. O que se observa na representação da Figura 2 abaixo.

Figura 2: Participação dos Usuários do Transporte Escolar.

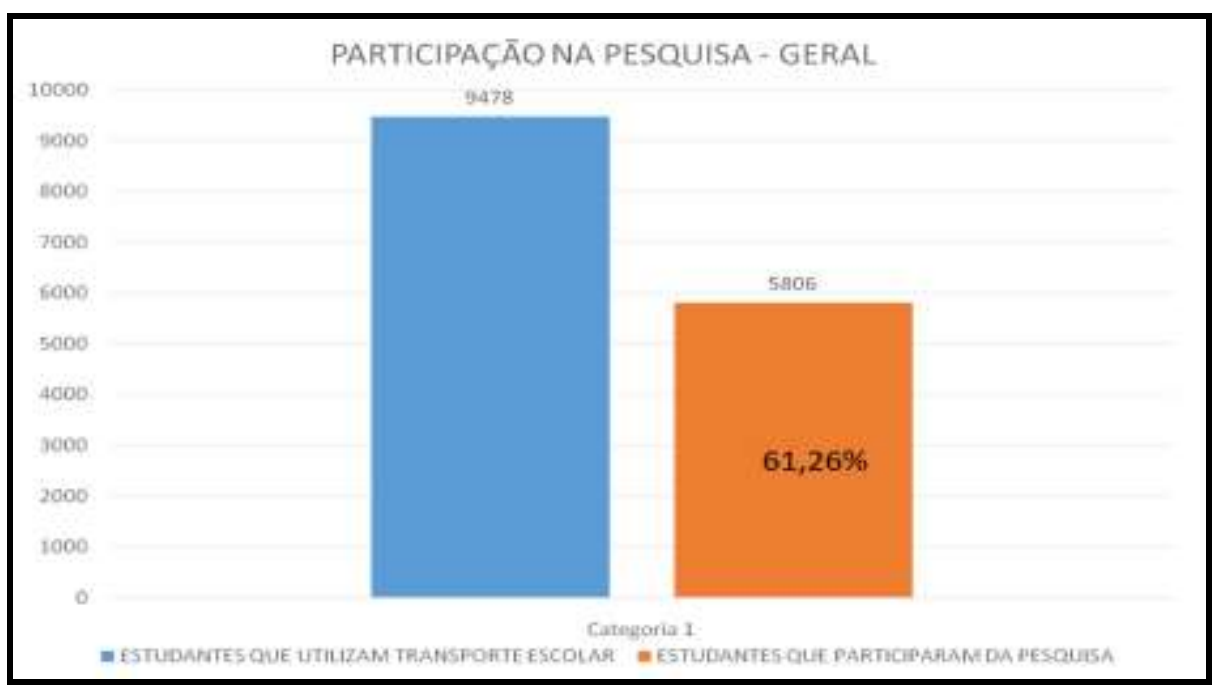

Fonte: Dados da pesquisa.

Nota-se que dos 9.478 estudantes usuários do Transporte Escolar 5.806 participaram da pesquisa, o que significa uma ótima participação, expressando a opinião de uma maioria, além do que envolvimento das escolas estaduais dos 22 municípios legitima os dados obtidos.

Com a finalidade de intervir numa situação, ou seja, mudar as condições negativas percebidas, tomou-se como parâmetro de análise dos dados a compreensão crítica dos fatos associados a luz da legislação e aos pré-requisitos básicos de qualidade do transporte escolar (resolução TCE/PE 06/2013). O monitoramento online teve como instrumento uma planilha, na qual as escolas que os estudantes utilizavam o transporte escolar preenchiam diariamente as ocorrências que eram analisadas 
em tempo real, pela CGPA/NAM e pela GAM/SEE, além do que era feito um contato telefônico com a (CGPA/NAM) duas vezes na semana para obter mais informações sobre os serviços, dirimir dúvidas. Todos esses dados eram discutidos em reuniões internas na Gerência de Articulação Municipal. GAM/SEE com o gerente, a coordenação do programa e os técnicos envolvidos no monitoramento, para encaminhamento e providências.

Quanto à pesquisa de satisfação dos estudantes foi organizada por blocos para melhor analisar os vários aspectos abordados:

Bloco 1 - Abrangência: quantitativo 9,478 estudantes usuários do transporte escolar, 5.806 participaram $61.26 \%$ da pesquisa conforme melhor a apresenta a Figura 3 a seguir.

Figura 3: Quantitativo de estudantes das Escolas Estaduais - Abrangência.

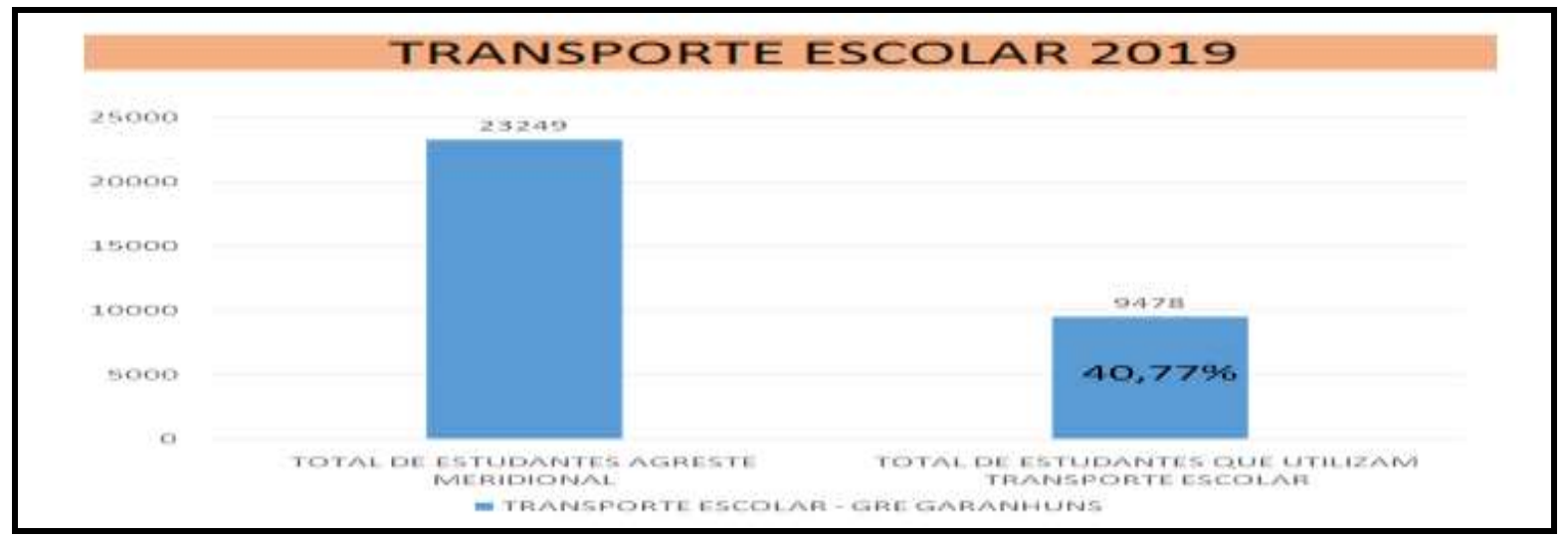

Fonte: Dados da pesquisa.

Bloco 2 Aspectos Gerais dos Veículos; veículos quebrados, veículos superlotados, veículos ocupados materiais dos caroneiros.

Figura 4: Superlotação do veículo.

\section{Veículo superlotado}

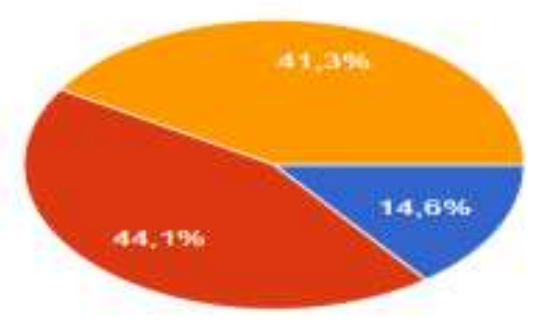


Figura 5: Ocupação com matérias dos caronas.

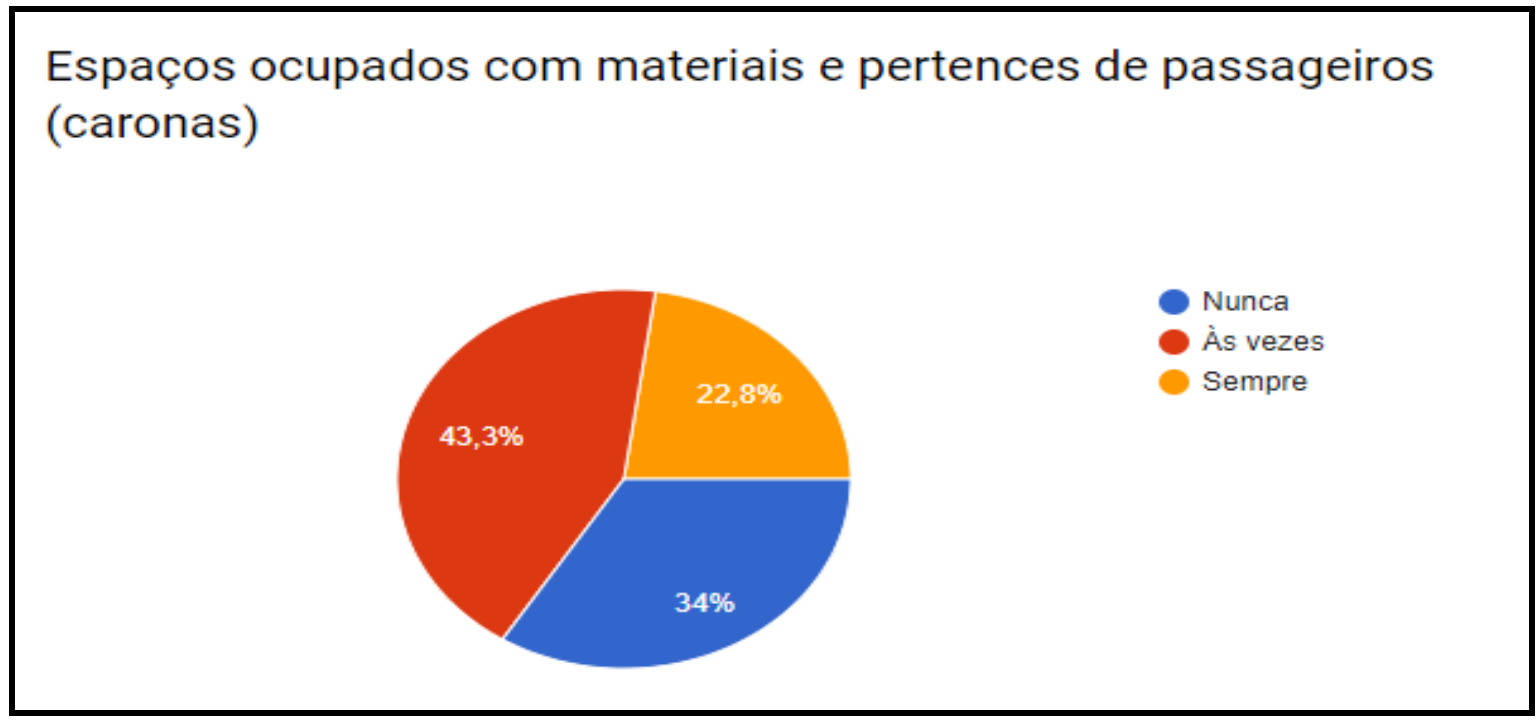

Fonte: Dados da pesquisa.

Percebeu-se neste gráfico que mais uma vez não existe uma preocupação de seguir as orientações, de que não é permitido o sistema de carona no transporte escolar, além do que caso ocorra um acidente quem será o provedor das despesas com os caroneiros?

Bloco 3: Aspectos Gerais do Condutor: dirigir alcoolizado, mandar substituto dirigir o veículo; cumprimento da velocidade permitida.

Figura 6: Condutor alcoolizado.

\section{Dirige o veículo alcoolizado?}

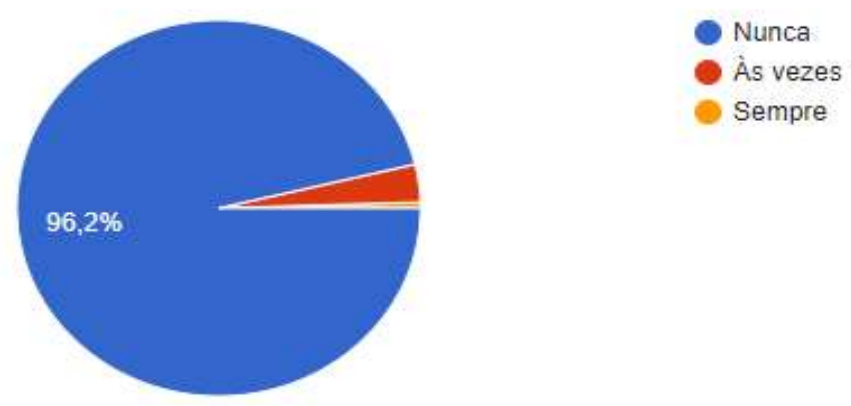

Fonte: Dados da pesquisa. 
Figura 7: Substituto.

\section{Manda substituto dirigir o veículo?}

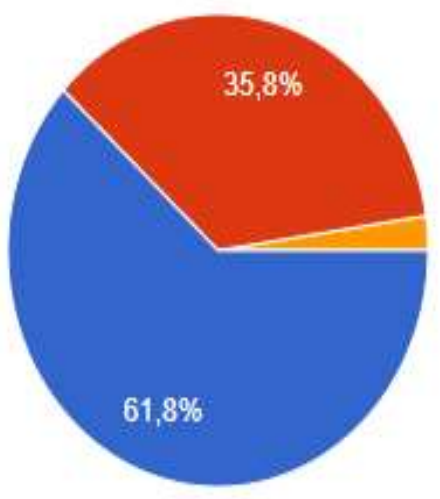

Fonte: Dados da pesquisa.

Figura 8: Condutor obedece a velocidade permitida.

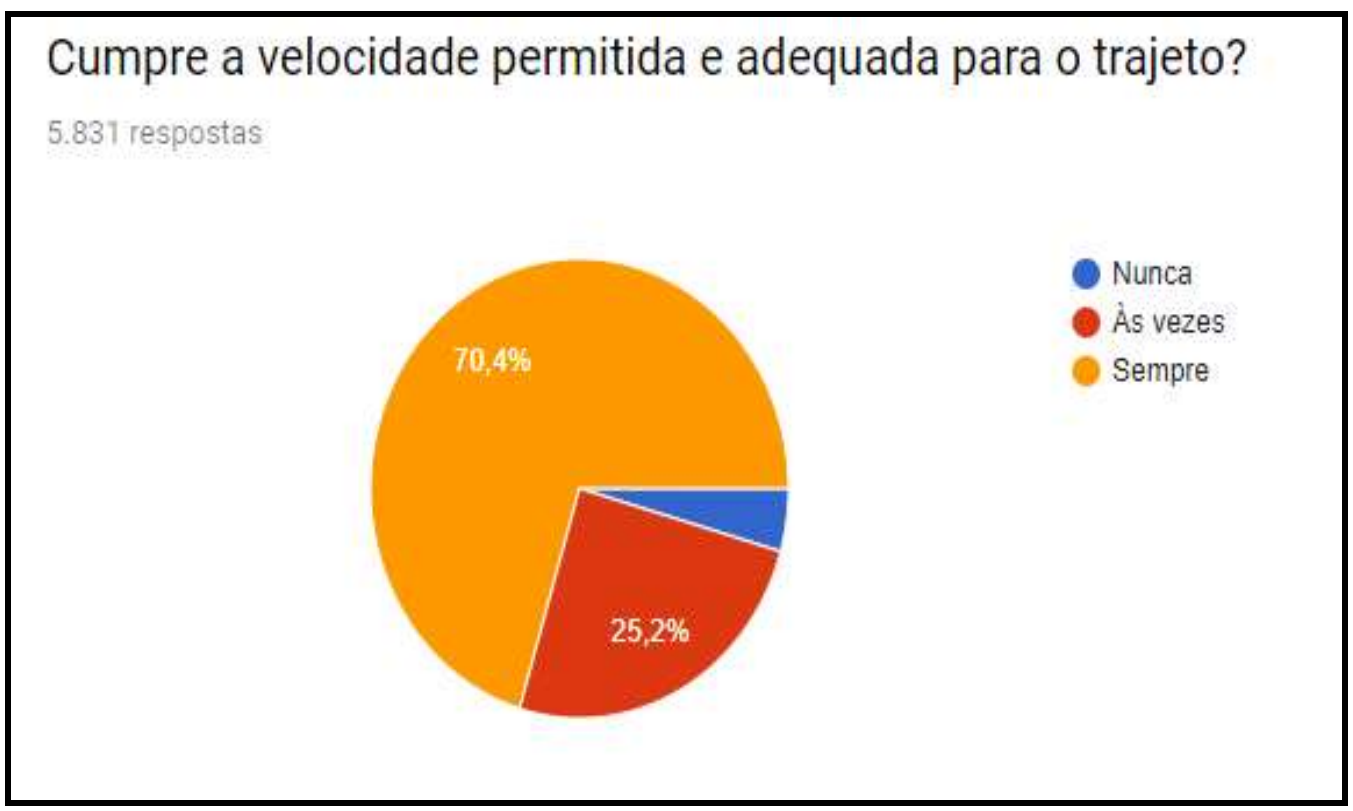

Fonte: Dados da pesquisa.

Percebeu-se nesses gráficos, o quanto a falta de segurança e risco estão bem próximos do dia a dia dos estudantes, o que não é permitido pela legislação do transporte escolar, especialmente quando se refere à contratação do condutor que tem que atender a uma série de pré-requisitos.

Bloco 4 Rotina dos Serviços de transporte escolar, garantia do transporte escolar todos os dias, pontualidade no cumprimento dos horários. 
Figura 9: Garantia do transporte diária.

\section{Garante o transporte todos os dias?}

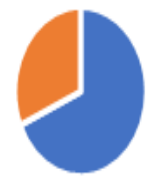

- Sim — Não

Fonte: Dados da pesquisa.

Figura 10: Condutor cumpre horário estabelecido

\section{É pontual no cumprimento do horário estabelecido?}

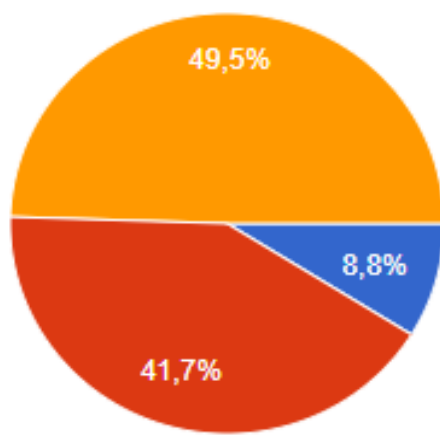

Nunca

Às vezes

Sempre

Fonte: Dados da pesquisa.

A oferta do transporte escolar deveria pautar-se na garantia de que todos os dias letivos sejam cumpridos de modo eficiente adequado, contínuo, isto é, ininterrupto e que o deslocamento dos estudantes obedecerá ao critério de pontualidade ao horário estabelecido pela unidade escolar.

Percebeu-se nestes gráficos que temos percentuais negativos de não cumprimento do acordado e contratado, afetando diretamente ao ensino aprendizagem do estudante implicando nos rendimentos finais.

Bloco 5 Acesso ao transporte escolar, tempo gasto até o ponto de embarque, atraso devido a não pontualidade do transporte. 
Figura 11: Acesso ao transporte escolar.

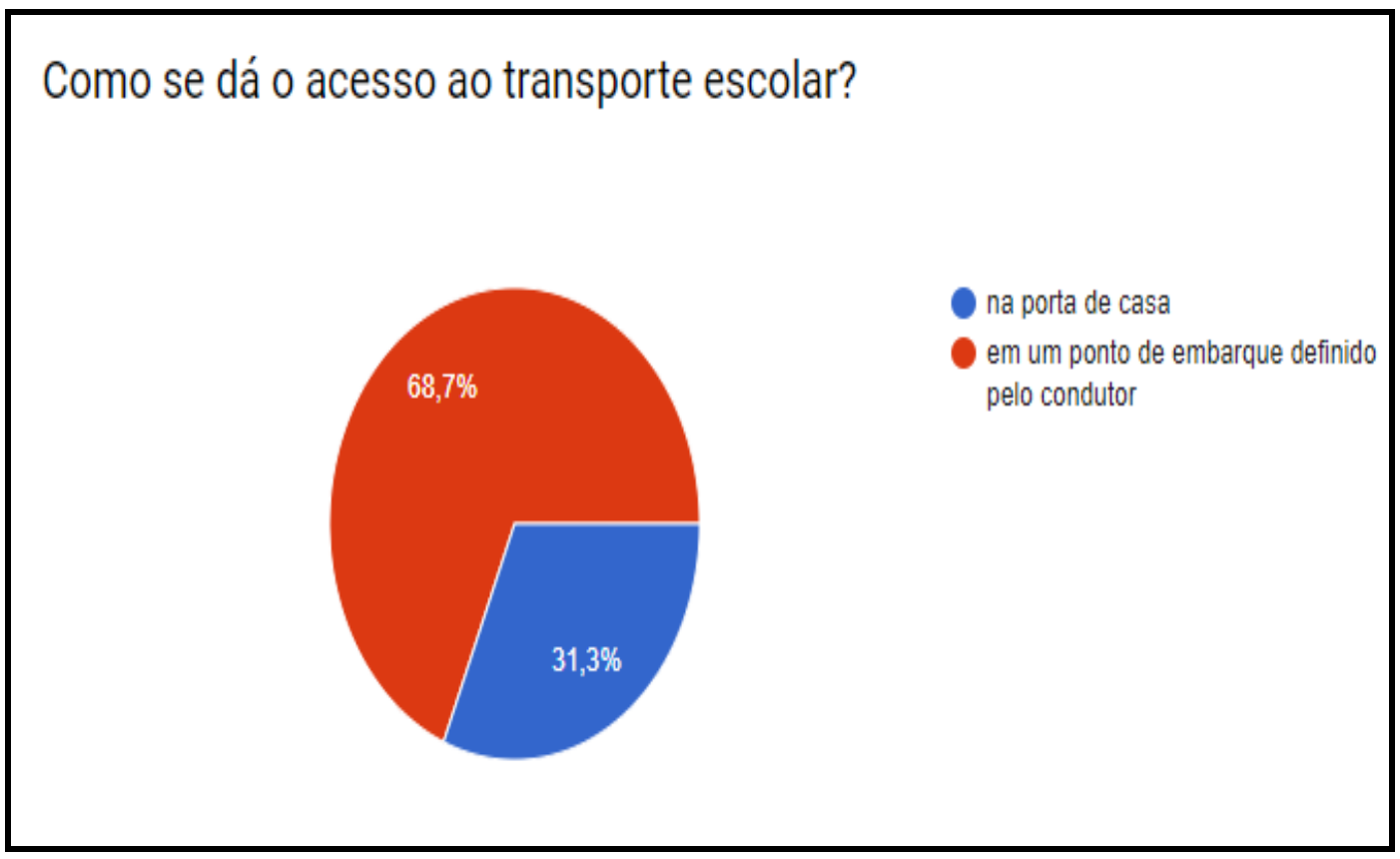

Fonte: Dados da pesquisa.

Figura 12: Tempo do trajeto casa - ponto de embarque.

\section{Em média, quanto tempo você gasta da sua casa até o ponto de embarque do transporte escolar?}

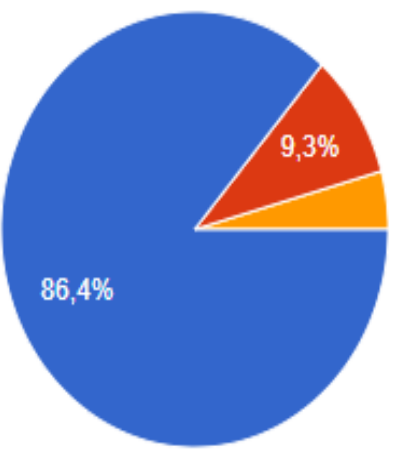


Figura 13: Atraso para chegar na escola causado pelo transporte escolar.

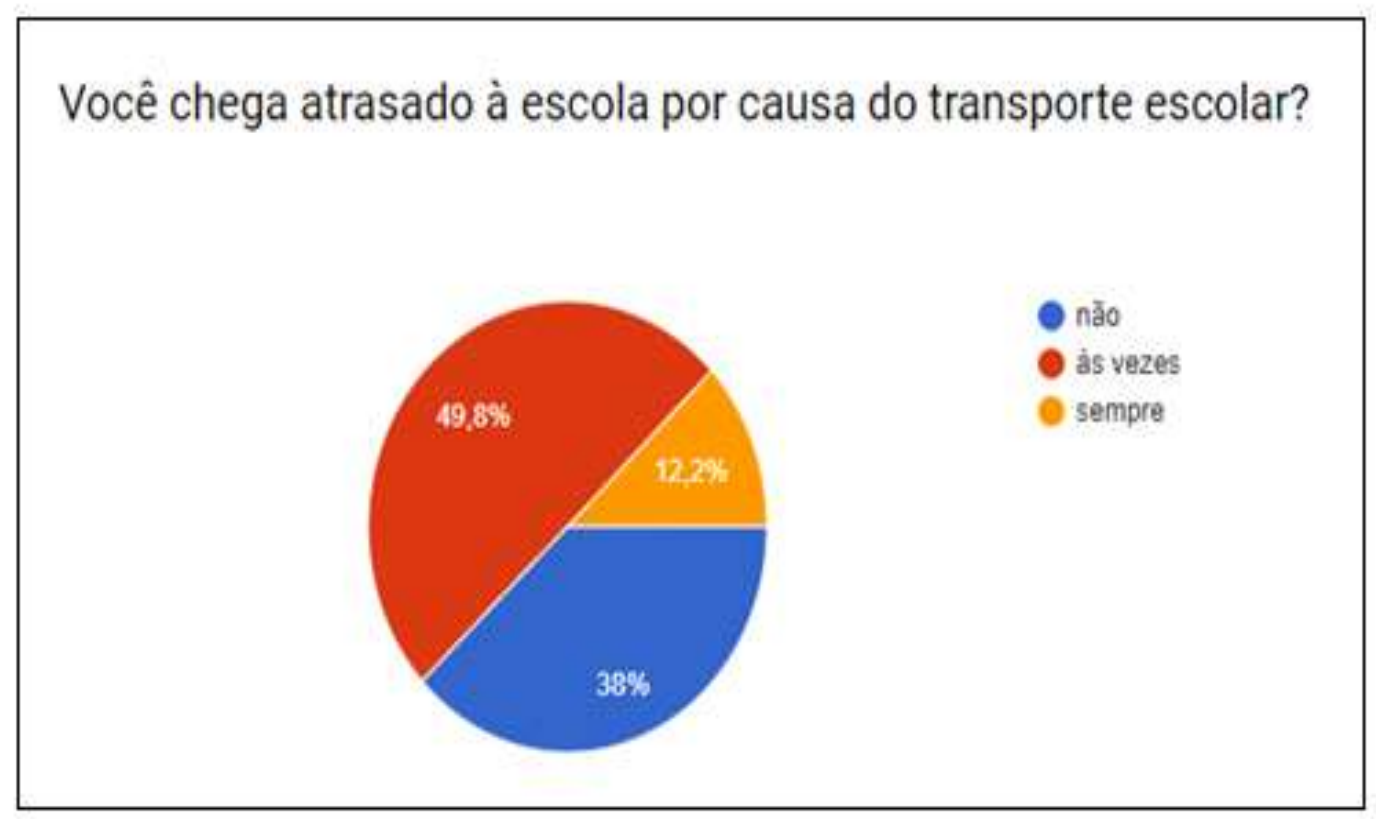

Fonte: Dados da pesquisa.

Mais uma vez nos deparamos com dados que implica diretamente no ensino aprendizagem, o tempo gasto pelo estudante até o ponto de embarque, atraso, implica no desempenho do estudante em sala de aula e consequentemente nos rendimentos finais.

Bloco 6 Nível geral de satisfação dos estudantes, os estudantes utilizam adequadamente o transporte escolar. Todas as respostas foram devidamente analisadas discutidas e algumas medidas foram encaminhadas e realizadas como reunião com os responsáveis pelas empresas contratadas para apresentação dos resultados da pesquisa.

Figura 14: Nível de satisfação.

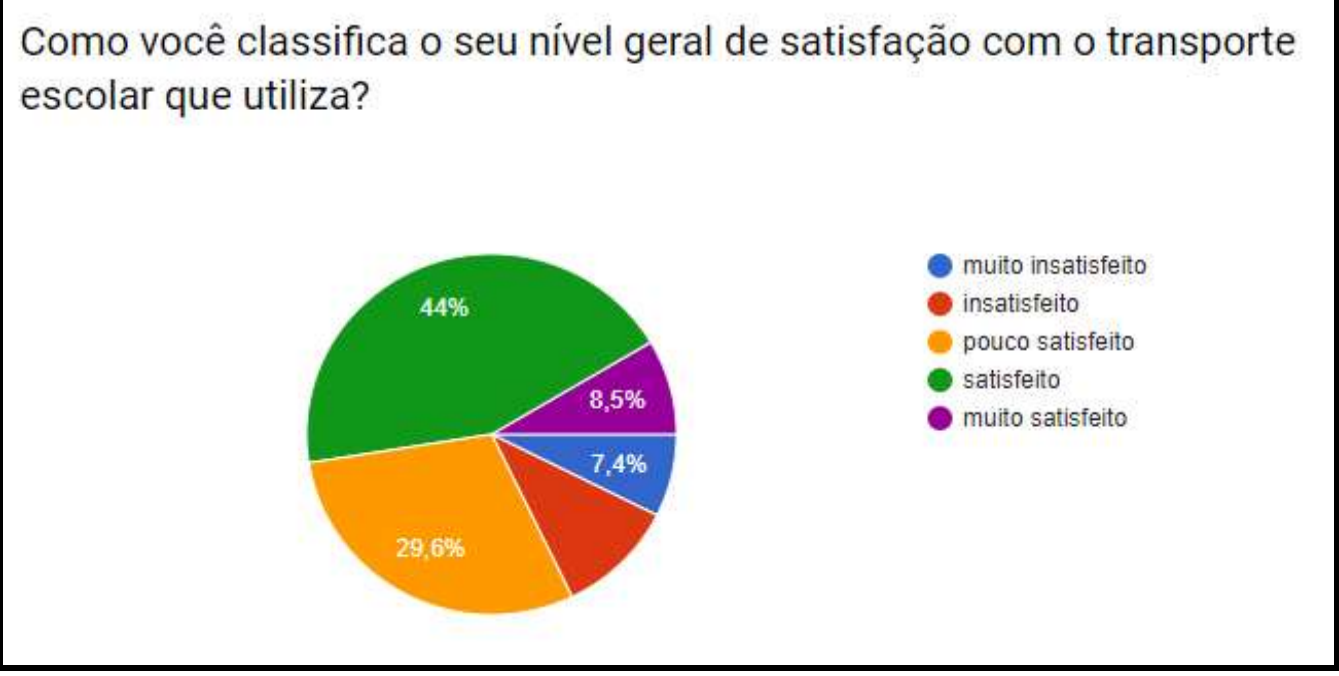

Fonte: Dados da pesquisa. 
Figura 15: Utilização adequada do transporte escolar.

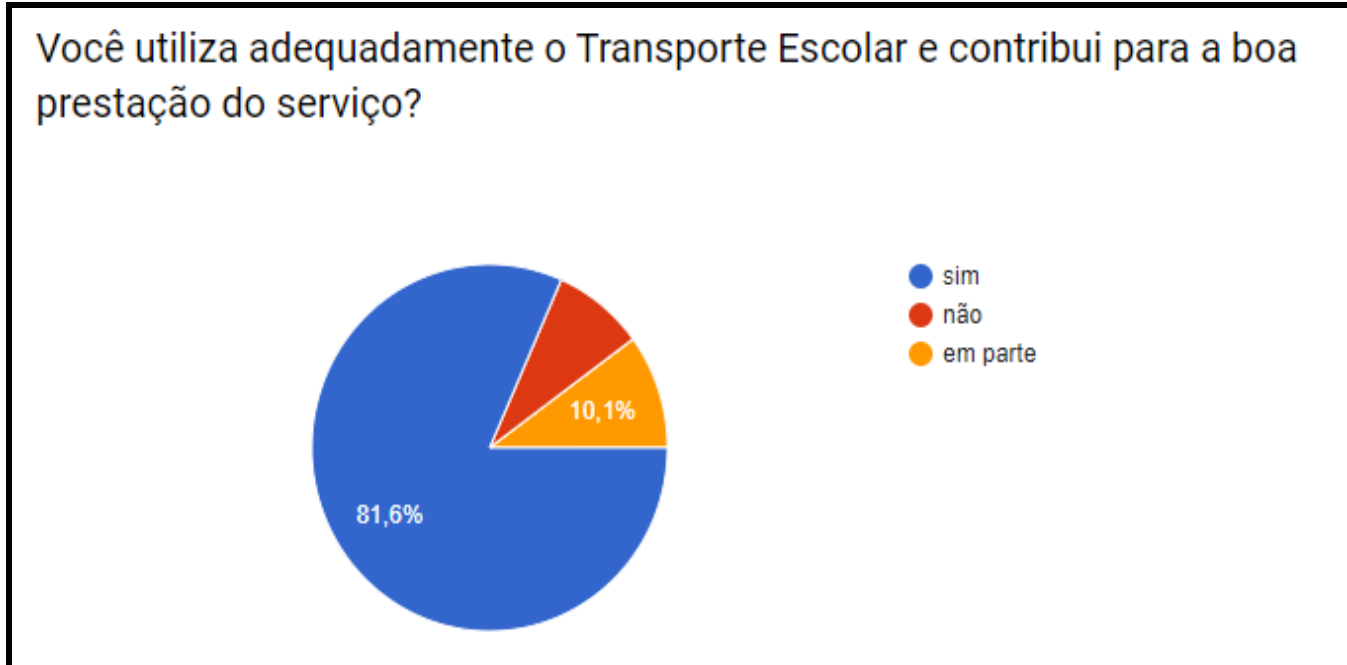

Fonte: Dados da pesquisa.

Os estudantes são o centro de todo contexto da capacidade de monitoramento da gestão do sistema de transporte escolar público no que se refere ao acesso e permanência na escola. Quanto ao nível de satisfação, o percentual de satisfeito $44 \%$ foi menor do que as soma dos outros percentuais que corresponde a 45,5\%. Quanto à utilização adequada do transporte, apesar do sim apresentar um percentual significativo de 81,6\%, os outros percentuais não deveriam aparecer pelo grau de importância do transporte escola.

Com esse monitoramento foram detectados problemas que se classificam da seguinte forma:

- $\quad$ Repetidos (sempre acontecem)

*Falta de conservação e preservação dos veículos;

*Atraso no deslocamento dos estudantes a escola;

*Superlotação;

*Paralização dos veículos por falta de pagamento a empresa.

- Ocasionais (acontecem de vez em quando)

* Motoristas não levam os estudantes após o término das aulas para casa;

*Estudantes matriculados em programas com calendário escolar diferenciado por ex: Programa Pro jovem durante o recesso do ensino regular não são atendidos com os serviços de transporte escolar;

*Estudantes do semi-integral alguns dias da semana não vão à escola por não ter transporte para voltar para casa.

Todos os problemas, sejam repetidos ou ocasionais, ferem o que determina a legislação da política pública de transporte escolar.

\section{Conclusão}

Obteve-se através da escuta aos estudantes, a descrição de como se deu, na realidade, a prestação dos serviços de transporte público escolar nos 22 municípios do Agreste Meridional especialmente as causas de sua paralisação.

A análise da aplicação dos instrumentos de monitoramento dos serviços de transporte escolar na Região do Agreste Meridional do Estado de Pernambuco teve o propósito de identificar a partir do próprio usuário como estava sendo ofertados os meios para garantir o seu direito à educação, acesso e permanência na escola. Constatou-se como resultados as seguintes irregularidades: déficit no fornecimento do transporte; más condições dos veículos; descumprimento de requisitos exigidos ao condutor; ausência de pontualidade, regularidade e segurança. De certeza forma, o monitoramento atendeu a expectativa e, ao 
mesmo tempo, mostrou-se efetivo na tomada de providências imediatas para sanar ou diminuir as irregularidades em tempo hábil evitando o prejuízo ao direito à educação.

Acredita-se que com esses resultados, fazem-se necessário urgentemente implementar novos elementos na gestão de monitoramento dos serviços de transporte escolar, da Gerência de Articulação Municipal (GAM/SEE) juntamente com as Gerências Regionais de Educação.

Destaca-se a importância da política pública de transporte escolar enquanto instrumento que viabiliza o direito à educação, à medida que não basta garantir vagas na escola, mas também garantir condições igualitárias de qualidade para todos, iniciando-se pela disponibilidade de um transporte escolar público seguro e sustentável o qual atenderia as condições de regularidade.

Os objetivos do trabalho foram, por ora, atingidos, uma vez que foi possível identificar os principais pontos propostos no tema em estudo. Mas como a produção científica não finda e há uma constante evolução quanto a importância dada a este tema. Vale ressaltar que este tipo de estudo é sempre bem-vindo para organizar e direcionar os entendimentos deste serviço de transporte. Assim, auxiliando tanto em novos trabalhos quanto aos tomadores de decisão para políticas públicas.

\section{Referências}

Álvares, L. M., \& Freitas, A. C. D. (2018). Pesquisa qualitativa em linguagem: trajeto (s) metodológico (s) da observação participante.

Brasil. (1988). Constituição Federal. Brasília.

Brasil. (1996). Lei n 9.394, Lei de Diretrizes e Bases da Educação Nacional, Ministério da Educação e Cultura. Brasília.

Brasil. (2016). Lei n ${ }^{\circ}$ 11.494/2007 Transporte Escolar no Brasil: Caminhos, Atalho e Contramão Projeto Prioridade Absoluta. São Paulo, Instituto Alana.

Brasil. (2014). Lei no 13.005. Aprova o Plano Nacional de Educação - PNE e dá outras providências.

Brasil. (2004). Lei No 10.880. Institui o Programa Nacional de Apoio ao Transporte do Escolar - PNATE e o Programa de Apoio aos Sistemas de Ensino para Atendimento à Educação de Jovens e Adultos, dispõe sobre o repasse de recursos financeiros do Programa Brasil Alfabetizado, altera o art. $4^{\circ}$ da Lei ${ }^{\circ}{ }^{9.424}$, de 24 de dezembro de 1996 , e dá outras providências.

Brasil. (2020). Lei No 16.882. Altera a Lei no 13.463, de 9 de junho de 2008, que institui o Programa Estadual de Transporte Escolar - PETE.

Brasil. (1990). Estatuto da Criança e do Adolescente. Lei federal, 8.

Benicio, F. C., Ferreira, A. V. O., Ferreira, A. L. C. M., Nascimento, A. L., Ferraz, A. D. R. L., \& Marquesan, F. F. S. (2020). Reflexões sobre o processo de formação de políticas públicas a partir do caso de Fortaleza-CE. Brazilian Journal of Development, 6(5), $22972-22999$.

Campos, H. D. et. al. (2017). A Inovação na Gestão Pública e a Eficiência dos Serviços Prestados aos Cidadãos. Revista Científica Multidisciplinar Núcleo do Conhecimento. 2(1), 309-318. ISSN:2448-0959.

Da Cruz, F. M. L. et al. (2008). A relação família-escola: fronteiras e possibilidades. Revista de Educação pública, 17(35), $443-454$.

Dardot, P., \& Laval, C. (2017). A nova razão do mundo: ensaio sobre a sociedade neoliberal. São Paulo: Boitempo.

Dos Santos, J. E. O. (2015). Políticas Públicas na Atualidade e seus Desafios. Website da Unisc. https://online.unisc.br/acadnet/anais/index.php/snpp/article/view/14322\#: :text=Denota\%2Dse\%20que\%20os\%20desafios,que\%20considerem\%20a\%20diver sidade\%20regional

Europeia, C. (2013). Guide to social innovation. Regional and Urban Policy. https://ec.europa.eu> ...>Liberary.

Fernandes, A. M., Bruchêz, A., d'Ávila, A. A. F., Castilhos, N. C., \& Olea, P. M. (2018). Metodologia de pesquisa de dissertações sobre inovação: Análise bibliométrica. Desafio online, 6(1).

Ferrarezi, E., \& Amorim, S. N. D. (2007). Concurso inovação na gestão pública federal no Brasil: análise de uma trajetória. https://repositorio.enap.gov.br>handle

Gonçalves, D. R., \& Wanzinack, C. (2001). A Importância do Transporte Escolar na Educação: Um Estudo de Caso sobre Transporte Escolar no Município de Guaratuba - Paraná. Revista da EMERJ, 4(13).

Hernández-Sampieri, R., \& Torres, C. P. M. (2018). Metodología de la investigación (4). México eD. F DF: McGraw-Hill Interamericana. https://corladancasch.com $>$ uploads $>2020 / 01>$ met....

Instituto Brasileiro de Geografia e Estatística. (2019). Síntese dos indicadores sociais: uma análise das condições de vida da população brasileira Rio de Janeiro, RJ: IBGE 
Research, Society and Development, v. 10, n. 16, e537101623991, 2021

(CC BY 4.0) | ISSN 2525-3409 | DOI: http://dx.doi.org/10.33448/rsd-v10i16.23991

Khedhaouria, A., Thurik, R. (2017). Configurational Conditions of National Innovation Capability: a fuzzy set analysis approach. Technological Forecasting and Social Change, Amsterdam,120, 48-58.

Lotta, G., Bauer, M., Rojas, C., \& Jobim, R. (2019). Trajetórias de implementação de mudanças no ensino médio nos estados brasileiros: impactos da Lei 13.415/2017. Artigo 3 IU Enapg. https://www.rescarchgate.net>..>Federalism

Mazetto, F. E. (2015). Estado, políticas públicas e neoliberalismo: um estudo teórico sobre as parcerias-público-privadas. Caderno de Estudos Interdisciplinares. https://publicacoes.unifal-mg.edu.br>cei>pdf_1

OECD. et al. (2005). Oslo manual: Guidelines for collecting and interpreting innovation data. Org. for Economic Cooperation \& Development. https://www.researchgate.net>271...

OSBORNE, S. P., \& BROWN, K. (2005). Managing change and innovation in public service 82 organizations. Routledge. www.sciencedirect.com>science>article>pii

Pereira A. S. et al. (2018). Metodologia da pesquisa científica. UFSM.

Pinheiro, T. G. B. S. (2013). Diagnóstico do transporte escolar rural público no município de Cachoeiro de Itapemirim-ES. Tese de Doutorado. Dissertação apresentada ao Programa de Pós-Graduação em Gestão Pública da Universidade Federal do Espírito Santo. Centro de Ciências Jurídicas e Econômicas Programa de Pós-Graduação em Gestão Pública. Vitória: UFES. https://www.escavador.com>sobre>4201379>theo-g...

Schons, D. L., Prado Filho, H. V., \& Galdino, J. F. (2020). Política Nacional de Inovação. Coleção Meira Mattos: revista das ciências militares, 14(49), 27-50.

Secchi, L. (2020). Análise de políticas públicas: diagnóstico de problemas, recomendação de soluções. Cengage Learning. https://scholar.google.com.br>citations

Silva, J. A. (2009). Curso de direito constitucional positivo. Malheiros.

Schuh, C., de Sousa, M. A. B., Ribeiro, S. P., \& da Costa Freitag, V. (2019). Análise de viabilidade do transporte escolar em município da região central do Rio Grande do Sul. Pensar Acadêmico, 17(3), 413-429.

Tavares, J. M. S. (2019). Política de transporte escolar e nucleação de escolas do campo: determinações gerais e especificidades na educação do município de Inhapi-AL (2010-2017).

Valle, A. C. C. A. (2013). Metodologia de inovação na gestão pública do estado de Minas Gerais. http://repositorio.fjp.mg.gov.br/consad/handle/123456789/719.

Vasconcellos, E.A. (1997). Transporte rural: o resgate de um tema esquecido. Revista dos Transportes Públicos, 75, 31 - 48.

Vergara, S. C. (2012). Projetos e relatórios de pesquisa em administração. São Paulo: Atlas.

Vieira, E. A. (1992). Democracia e política social. São Paulo: Cortez; Autores Associados, Coleção Polêmicas do Nosso Tempo, 49.

Zani, F. B., \& Spinelli, R. Q. (2010). Inovação na gestão pública: eficiência com participação? http://www.anpad.org.br/admin/pdf/apb139.pdf. 